\title{
$\operatorname{coNF}-961105-4$
}

\section{CRASHWORTHINESS OF THE AT-400A SHIPPING CONTAINER'}

\author{
Jeffrey D. Gruda \\ Material and Structural Mechanics Department \\ Sandia National Laboratories \\ Albuquerque, New Mexico \\ Allen R. York, II \\ Engineering and Processes Department \\ Sandia National Laboratories \\ Albuquerque, New Mexico
}

\begin{abstract}
Shipping containers used for transporting radioactive material must be certified using federal regulations. These regulations require the container be tested or evaluated in severe mechanical and thermal environments which represent hypothetical accident scenarios. The containers are certified if the inner container remains leaktight. This paper presents results from finite element simulations of the accidents which include subjecting the AT-400A to a 30 foot $(9 \mathrm{~m})$ drop onto an unyielding target and crushing the container with an $1100 \mathrm{lb}(500 \mathrm{~kg})$ steel plate dropped from 30 feet $(9 \mathrm{~m})$. The nonlinear PRONTO3D finite element results were validated using test results. The simulations of the various impacts and crushes identified trends and worst-case orientations. They also showed that there is a significant margin of safety based on the failure of the containment vessel.
\end{abstract}

\section{INTRODUCTION}

The AT-400A is a Department of Energy (DOE) shipping container (Figure 1) used to transport and store plutonium from dismantled nuclear weapons. To obtain certification, the container has to pass stringent structural and thermal tests defined in 10 CFR 71 (Title 10, Code of Federal Regulations, Part 71). This paper presents analyses done to determine if the containment vessel (CV) retains its integrity following abnormal mechanical environments. The analyses included simulating a 30 foot drop onto a unyielding target and the crush of the container between an $1100 \mathrm{lb}$ plate dropped from 30 feet and an unyielding target, both in various orientations.

The objective of the analyses described in this paper is to provide an understanding of how the AT-400A responds to accident environments. The emphasis is placed on determining the gross response of the CV. The contents support fixture is crudely modeled but approximates the correct loading condition on the $\mathrm{CV}$ through the transition flange. No attempt is made here to examine the response of the contents in the AT-

'This work was supported by the U. S. Department of Energy under Contract No. DEAC04-94AL85000
$400 \mathrm{~A}$.

The response of the container leads to conclusions about the safety margin and the ability of the AT- $400 \mathrm{~A}$ to survive abnormal mechanical environments. Once verified, the analyses will provide insight into the most damaging orientation(s). The results section discuss these issues.

Finally, due to the complexity of the AT-400A, a reasonably sized model was constructed using may approximations and assumptions. This was done to keep the model small but supply reasonably accurate results. The size of the model was important since cost and turnaround time were important to the project.

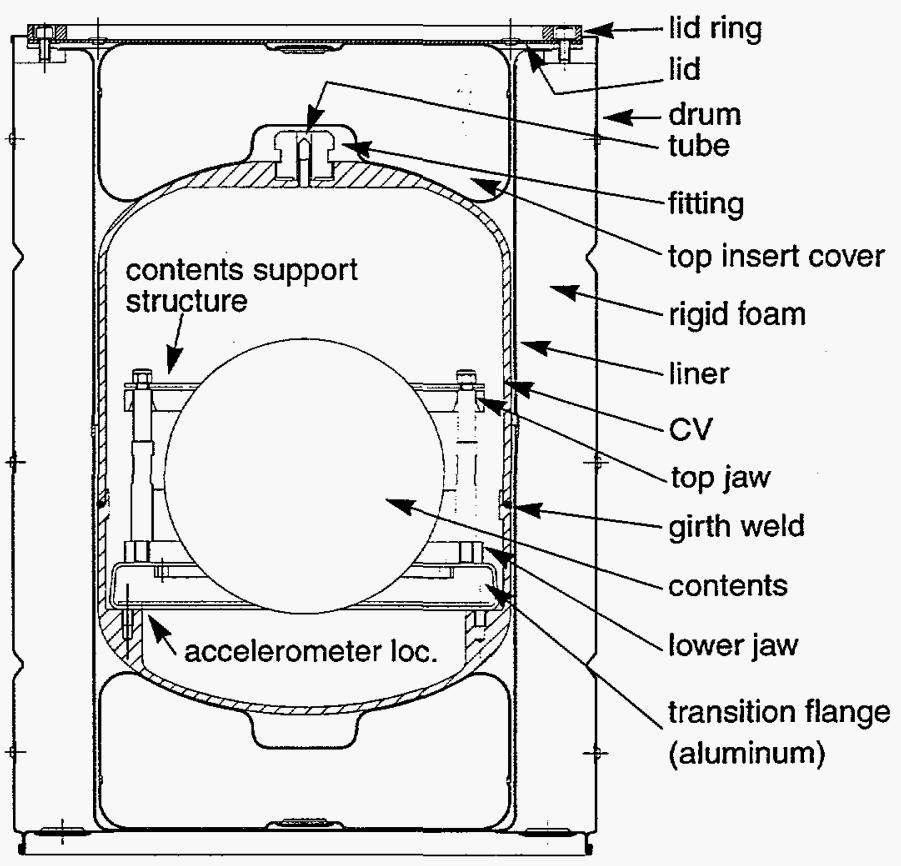

FIGURE 1: AT-400A SHIPPING CONTAINER 


\section{DISCLAIMER}

This report was prepared as an account of work sponsored by an agency of the United States Government. Neither the United States Government nor any agency thereof, nor any of their employees, makes any warranty, express or implied, or assumes any legal liability or responsibility for the accuracy, completeness, or usefulness of any information, apparatus, product, or process disclosed, or represents that its use would not infringe privately owned rights. Reference herein to any specific commercial product, process, or service by trade name, trademark, manufacturer, or otherwise does not necessarily constitute or imply its endorsement, recommendation, or favoring by the United States Government or any agency thereof. The views and opinions of authors expressed herein do not necessarily state or reflect those of the United States Government or any agency thereof. 


\section{DISCLAIMER}

Portions of this document may be illegible in electronic image products. Images are produced from the best available original document. 


\section{METHODOLOGY}

\section{Container Description}

The AT-400A consists of a 0.048 in. $(1.2 \mathrm{~mm})$ thick $304 \mathrm{~L}$ stainless steel outer drum $(20 \mathrm{in} .(51 \mathrm{~cm})$ diameter $x 30$ in. $(76 \mathrm{~cm})$ height $)$ that, with a $0.075 \mathrm{in}$. (1.9 mm) thick $304 \mathrm{~L}$ liner, forms a cavity that is filled with rigid, intumescent polyurethane foam. Two 0.075 in. $(1.9 \mathrm{~mm})$ $304 \mathrm{~L}$ insert covers, also filled with foam, surround the all-welded containment vessel on top and bottom. The CV is nominally 0.25 in. (0.64 $\mathrm{cm}$ ) thick, and is also fabricated from 304L. A Nitronic 60 fitting threads into the top of the CV to protect the tube which is used to purge and backfill the $\mathrm{CV}$ before it is welded closed. An aluminum transition flange mounts inside the $\mathrm{CV}$ to fasten the contents to the $\mathrm{CV}$ flange.

\section{Model Definition}

The AT-400A analyses were done using PRONTO3D (Taylor, 1987), a nonlinear finite element (FE) code developed by Sandia National Laboratories. PRONTO3D provides many useful options needed to simulate abnormal environments. The options include the ability to model materials which include foam and stainless steel, and the ability to define numerous contacts quickly and easily. The FE mesh, consisting of approximately 26,000 hex and shell elements, is shown in Figure 2 and was constructed using PATRAN (PDA Eng, 1987). This model is called FE Model 1. Another model, called FE Model 3, did not incorporate the lid ring. Shells with increased thickness simulated the ring. Yet another variation, called FE Model 2, used a lower density top insert cover.

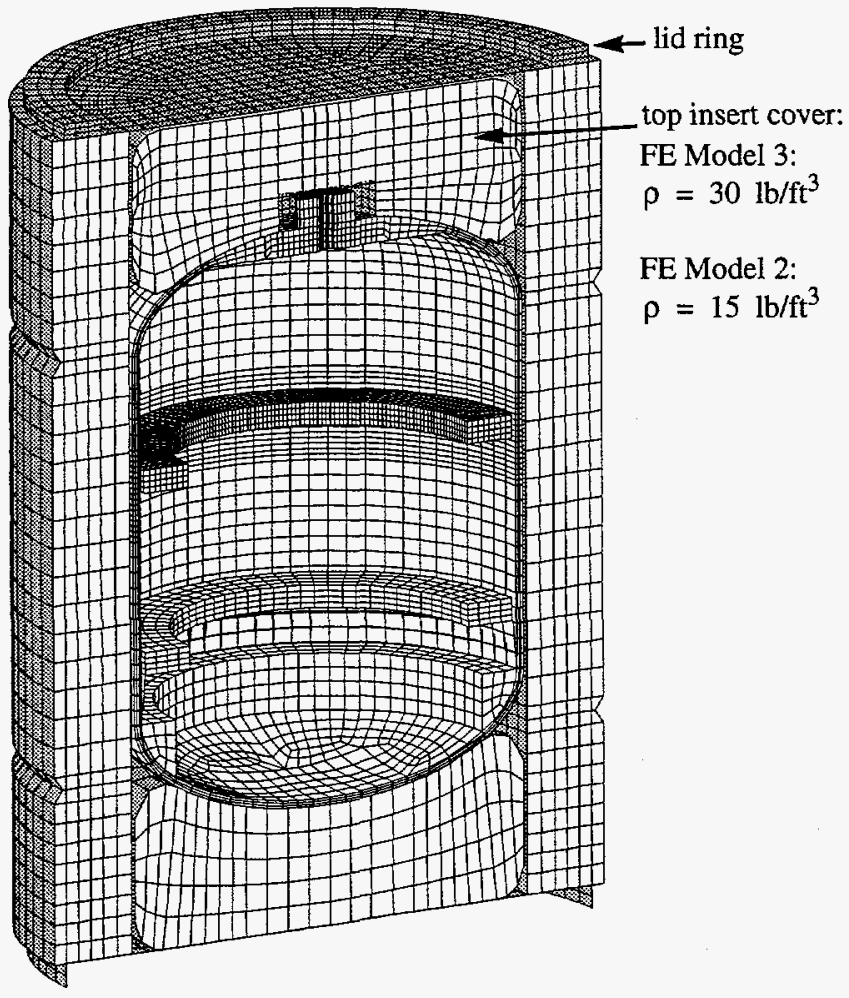

FIGURE 2: FINITE ELEMENT MODEL OF THE AT-400A
All of the FE models crudely approximate the contents and support structure since the deformations of these items is not of interest, but the correct loading to the CV is desired. However, contacts and gaps that open and close, which are important in determining the response of the container, are accurately modeled. The $\mathrm{CV}$ and both insert covers are able to slide relative to one another and relative to the drum.

\section{FEA Model - Assumptions and Approximations}

In numerical simulations there are always simplifying or idealizing assumptions. These assumptions should not cause the numerical results to significantly deviate from the experimental results. The assumptions used in the analyses are outlined below. They are listed in order from most significant to the least. That is, the more the significant assumptions are thought to contribute more to differences between actual tests and numerical simulations. The order is subjective, and no effort is made to quantify the affect any of these assumptions. It should be noted that these assumptions are mainly used to provide a conservative approach as far as CV survivability is concerned.

Impact Orientations. The test orientations are not exactly the same as simulated due to experimental error. For example, it is demonstrated analytically that a one degree deviation in impact angle causes significant differences deformations.

Yield Stress for 304L. The yield stress for the 304L steel components is set at $25 \mathrm{ksi}$ (173 MPa) because the specifications governing most of the $304 \mathrm{~L}$ material do allow this as a minimum. In reality the yield stress is closer to $33 \mathrm{ksi}(229 \mathrm{MPa})$ for the $304 \mathrm{~L}$ components. However, the lower value ensures the calculations are conservative.

Material Thickness. Most of the sheet metal parts are assumed to have the minimum thickness allowed on the fabrication drawings. In reality the minimum thicknesses typically occur at bends or where the metal has been worked. It is not feasible to have a model with varying metal thicknesses due to the uncertainty in the actual thickness distribution. The smaller thicknesses make the FE model conservative.

Strain Rates. The numerical model does not use a strain rate dependent material model for any of the materials. The foam shows the greatest change in properties between static and dynamic loading. The majority of the AT-400A simulations were run with dynamic foam material properties since they appear to give better agreement with experimental results. That is, properties that were determined from dynamic rather than static testing. The stronger (dynamic) foam properties also result in higher forces exerted on the CV.

Foam Density. In the FE model, the foam density is assumed to be perfectly uniform. Actually, there can be up to a $10 \%$ density variation as the foam is poured and cured in the drum vertically. The variation in density also causes a variation in strength which is not taken into account.

Drum Screws. The drum screws which secure the lid to the container were not simulated due to excessive costs in doing so. The drum lid is modeled as though it is welded to the drum. 
CV Location. In all of the simulations, the $\mathrm{CV}$ is located in the geometric center of the AT-400A just prior to impact. In reality, the CV is probably in contact with the liner and/or the insert covers.

Girth Weld Joint. The girth weld and backing on the $\mathrm{CV}$ were not a part of the FE model. A continuous 0.25 in. $(0.64 \mathrm{~cm})$ thickness was used instead which is conservative because of the reduced thickness.

\section{Material Properties}

The 304L stainless steel material model uses the power law hardening constitutive model shown in Figure 3 with a yield stress, $\sigma_{\text {ys }}$, of 25 $\mathrm{ksi}(173 \mathrm{MPa})$ and where $\varepsilon_{\mathrm{p}}$ is the equivalent plastic strain and $\bar{\sigma}$ is the effective plastic stress. Additional material properties for $304 \mathrm{~L}$ and other metals are listed in Table 1.

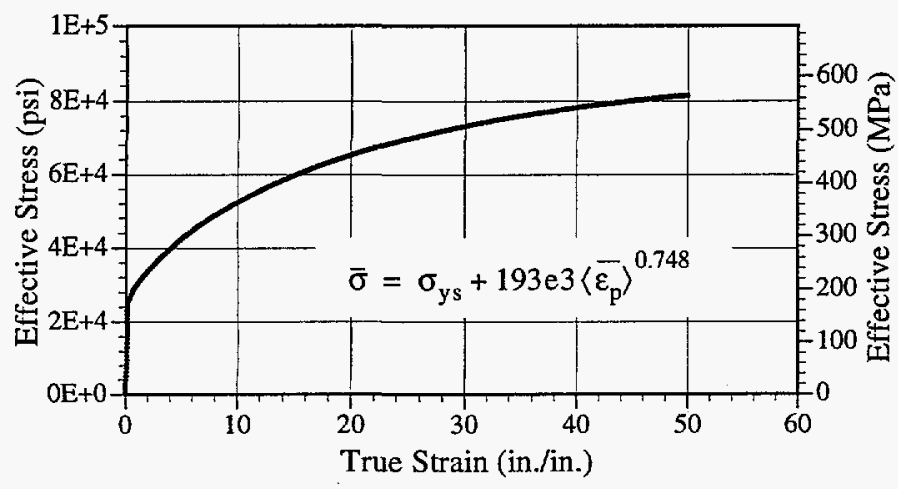

FIGURE 3: 304L NONLINEAR PROPERTIES

The foam is modeled with the orthotropic crush model in PRONTO3D. In uniaxial crush the properties of the foam are shown in Figure 4.

TABLE 1: MATERIAL PROPERTIES

\begin{tabular}{|c|c|c|c|}
\hline Material & $\begin{array}{c}\text { Young's Modulus } \\
(\mathrm{psi}(\mathrm{GPa}))\end{array}$ & $\begin{array}{c}\text { Poisson's } \\
\text { Ratio }\end{array}$ & $\begin{array}{c}\text { Yield Stress } \\
(\mathrm{psi}(\mathrm{MPa}))\end{array}$ \\
\hline \hline 304L SS & $28 \times 10^{6}(194)$ & 0.27 & $25,000(173)$ \\
\hline Nitronic 60 & $28 \times 10^{6}(194)$ & 0.27 & $50,000(346)$ \\
\hline 1100 aluminum & $10 \times 10^{6}(69)$ & 0.33 & $4,500(31)$ \\
\hline
\end{tabular}

\section{FINITE ELEMENT MODEL VALIDATION}

\section{Qualitative Comparison of Deformed Shape}

Unit SCU-1 is the designator for a full-scale AT-400A unit that was subjected to a 30 foot $(9 \mathrm{~m})$ drop, dynamic crush, puncture, and fire tests. An X-ray of SCU-1 is shown in Figure 5 that was taken after the drop and dynamic crush tests. A deformed plot of the FE simulation after the crush is illustrated below. Note that the test unit was subjected to a drop and crush test, while the simulation only shows the deformation after a crush. Currently, calculations can only be done for a single loading condition like a crush or a drop but not in series.

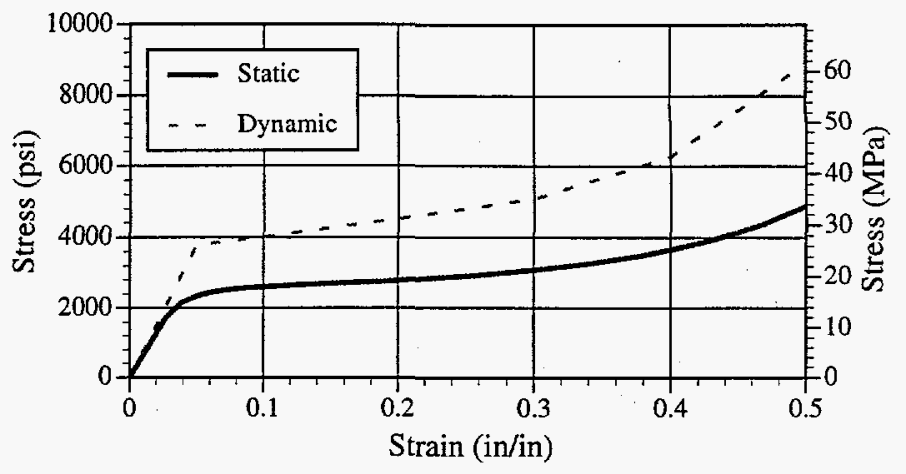

FIGURE 4: RIGID FOAM PROPERTIES

From Figure 5, it can be seen that the deformation patterns are similar. The lid has several noticeable buckles in both cases. Also, the CV is significantly deformed in both cases, with more deformation shown in the $x$-ray. This is expected since the test unit was also subjected to a free drop. The outer drums show more deformation (reduction in diameter) at the ends than at the middle in both cases.
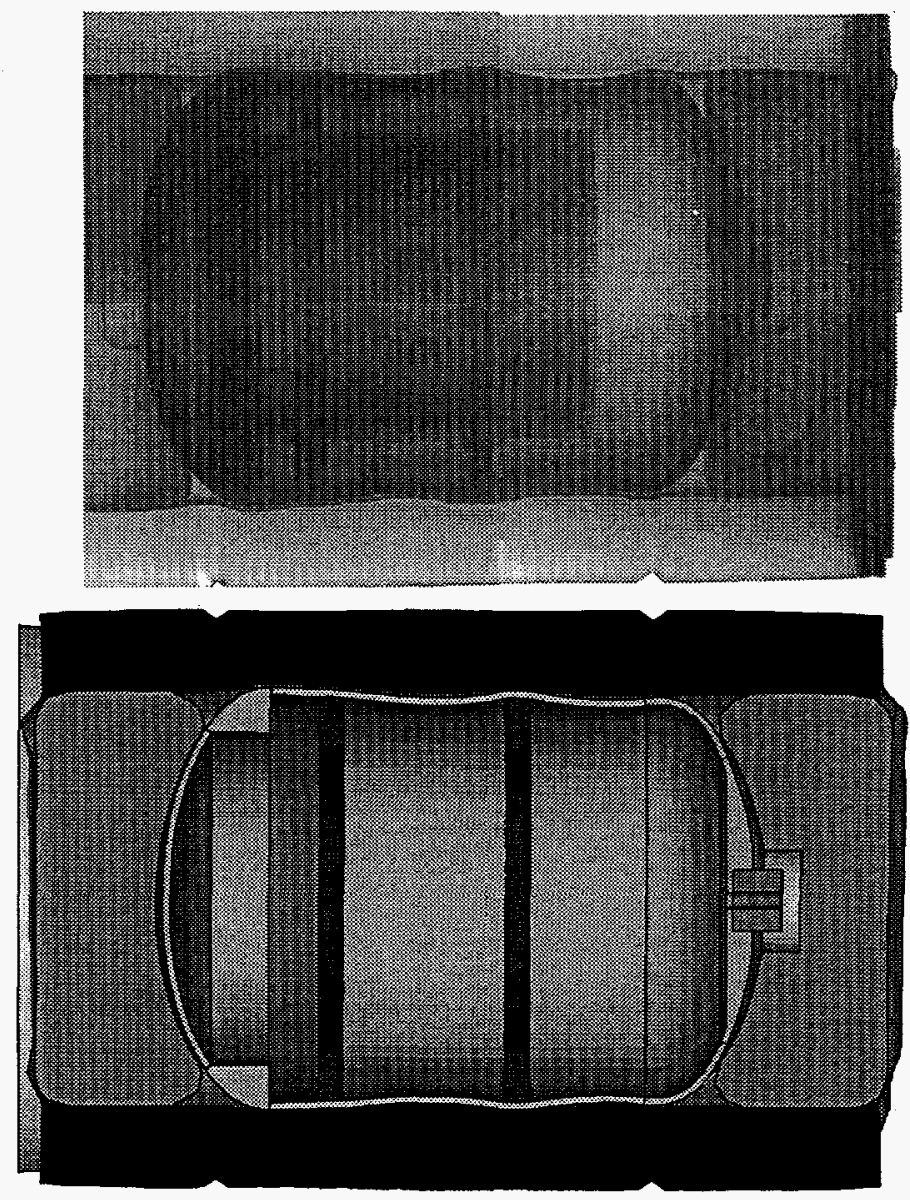

FIGURE 5: SCU-1 DEFORMED SHAPE (X-RAY) AFTER DROP AND CRUSH TESTS (TOP) AND CRUSH SIMULATION DEFORMED SHAPE (BOTTOM) 


\section{Quantitative Comparisons Between Simulation and Test}

CV Accelerations. A full-scale test unit was subjected to a four foot drop onto an unyielding target. Figure 6 shows a comparison of acceleration histories of the CV flange. Reference Figure 1 for the accelerometer location. The peak accelerations were $200 \mathrm{G}$ 's and 208 G's for the test and analysis, respectively, which is agreement within $4 \%$. The integrated accelerations indicate velocity changes of $22.2 \mathrm{ft} . / \mathrm{s}$ and $22.9 \mathrm{ft} . / \mathrm{s}$ for the test and analysis, respectively.

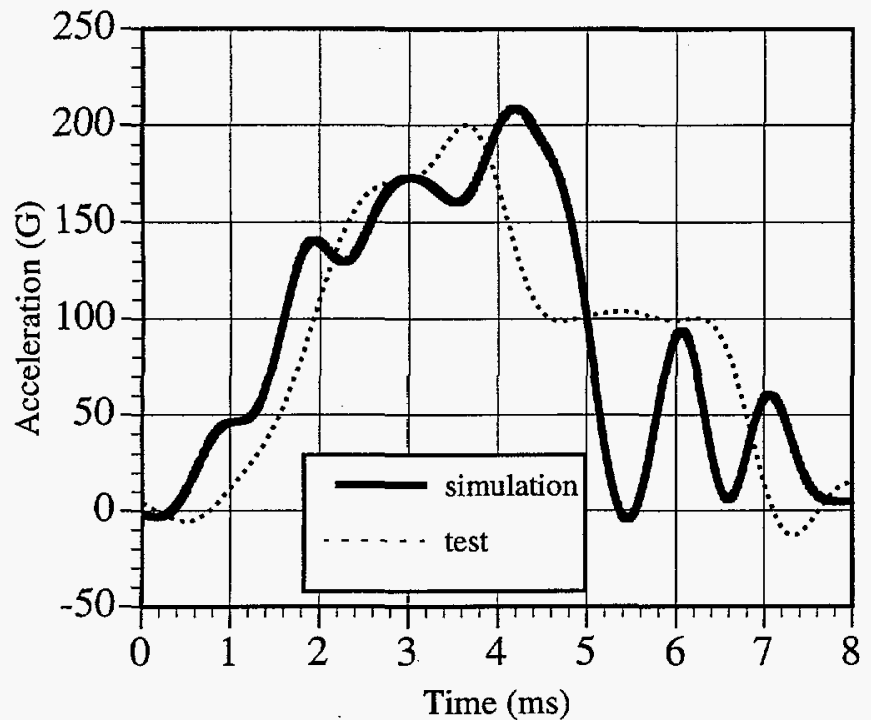

FIGURE 6: COMPARISON OF CV ACCELERATION HISTORY DURING A FOUR-FOOT DROP

The plateau in the test acceleration history is attributed to the deformation of the transition flange. The FE model uses a simplified approximation to attach the transition flange to the $\mathrm{CV}$. The approximation assumes that the lower portion of the transition flange is integrally attached to the CV. In actuality it is only attached in six places. It was observed in testing that the transition flange deforms significantly in a 4-foot drop $(1.2 \mathrm{~m})$ between the points where it is attached to the CV. However, the transition flange in the FE model flexes elastically allowing the simulated contents to oscillate. It is believed that this is the source of the oscillations in the acceleration history from the analysis which begins at about $5 \mathrm{~ms}$.

SEU-4 30 foot Drop Test. A full-scale test unit, designated SEU-4, was subjected to a 30 foot $(9 \mathrm{~m})$ drop test in a top down orientation. In the test, the transition flange failed affecting the accelerations measured on the CV flange. A comparison of measured accelerations to the simulation could not be made since the FE model does not capture material failure. However, the gross response of the test and simulations can be compared by examining the velocity changes predicted for the CV. Table 2 lists the velocity changes for the test and two FE simulations using slightly different models. Model 1 includes the lid ring and is shown in Figure 2. Model 3 does not include the ring, and the ring thickness is accounted for in the shells on the top of the drum. Model 1 is the closest to the test configuration. The test showed a velocity change of $57.3 \mathrm{ft} / \mathrm{s}(17.5 \mathrm{~m} / \mathrm{s})$.
TABLE 2: CALCULATED VELOCITY CHANGES FOR SEU-4 TEST AND ANALYSES

\begin{tabular}{|c|c|c|}
\hline Description & $\begin{array}{c}\text { CV Flange } \Delta \mathrm{V} \\
(\mathrm{ft} / \mathrm{s}(\mathrm{m} / \mathrm{s}))\end{array}$ & $\begin{array}{c}\% \text { Diff.: Test and } \\
\text { Simulation }\end{array}$ \\
\hline \hline Analysis - FE Model 1 & $59.1(18.0)$ & 3.1 \\
\hline Analysis - FE Model 3 & $60.0(18.3)$ & 4.7 \\
\hline
\end{tabular}

Lid Deflection During CG-Over-Corner Drop Test. There were several tests conducted to evaluate various lid designs. The parameters varied in the tests were lid thickness and method of attachment to the thick ring on top of the lid. The FE model did not simulate the various attachment methods. Only the lid thickness in the simulation was varied. However, Table 3 shows that there is reasonable agreement between the numerical model and the tests. The parameter that is compared is the maximum deformation of the lid. Figure 7 illustrates the deformed plots with various lid thicknesses.

TABLE 3: COMPARISON OF LID DEFLECTIONS WITH INCREASED LID THICKNESS

\begin{tabular}{|c|c|c|c|}
\hline $\begin{array}{c}\text { Lid Thickness } \\
\text { (in.(mm)) }\end{array}$ & \multicolumn{2}{|c|}{$\begin{array}{c}\text { Max. Deflection (in. (cm)) } \\
\text { Sest }\end{array}$} & $\begin{array}{c}\% \\
\text { Difference }\end{array}$ \\
\hline \hline $0.048(1.2)$ & $1.14(28.9)$ & $1.8(45.7)$ & $-37^{\mathrm{a}}$ \\
\hline $0.075(1.9)$ & $0.923(23.4)$ & $1.0-1.1(25.4-27.9)$ & 7.7 to 16.1 \\
\hline $0.090(2.3)$ & $0.824(20.9)$ & $0.6-0.9(15.2-22.8)$ & -37 to -8.4 \\
\hline
\end{tabular}

a. The lid had gross plastic deformation and material failure. The material failed due to the bearing stresses from the screws. Material failure is not included in the simulations. Thus simulation deflections should be less.

\section{STRUCTURAL ANALYSES}

The analyses of the containers were done for two hypothetical accident conditions: 1$)$ a drop from 30 feet $(9 \mathrm{~m})$ onto an unyielding target, and 2) a crush with an 1,100 pound rigid plate dropped from 30 feet ( 9 $\mathrm{m})$. These two scenarios were simulated with the container in various orientations which included side, top, and cg-over-corner. A matrix of the analyses completed is shown in Table 4.

\section{DISCUSSION OF RESULTS}

\section{Perturbation in Drop Orientation}

As stated in the section on assumptions and approximations, the deformation during impact is dependent on impact orientation. Table 5 lists $\mathrm{CV}$ deformations from a side impact. There is as much as a $55 \%$ difference between the two orientations.

\section{Worst Case for CV}

It appears that the worst orientation for overall plastic deformation of the $\mathrm{CV}$ is the side crush (Figure 11). The top crush has slightly higher plastic strains in the $\mathrm{CV}$, but they are localized. However, even the highest level of true plastic strain is extremely low $(\sim 8 \%)$ compared those that fail 304L stainless steel $(\sim 70 \%)$. 


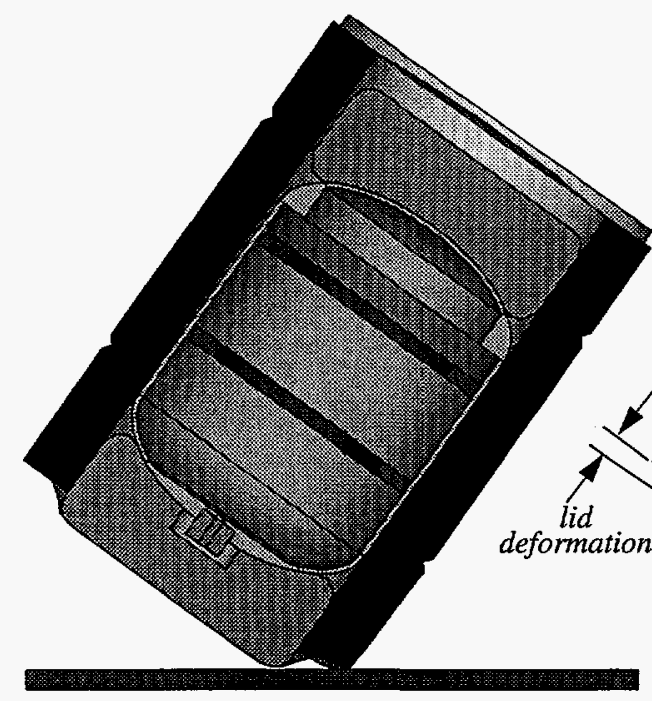

0.048 in. $(1.2 \mathrm{~mm})$

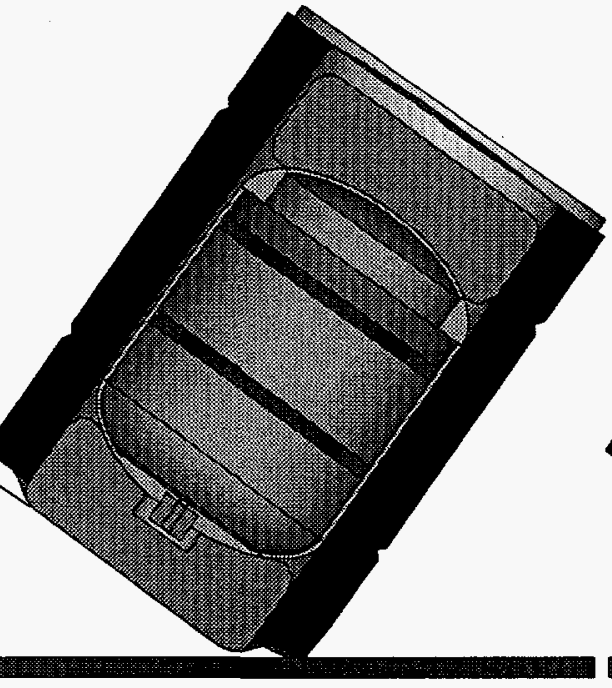

0.075 in. $(1.9 \mathrm{~mm})$

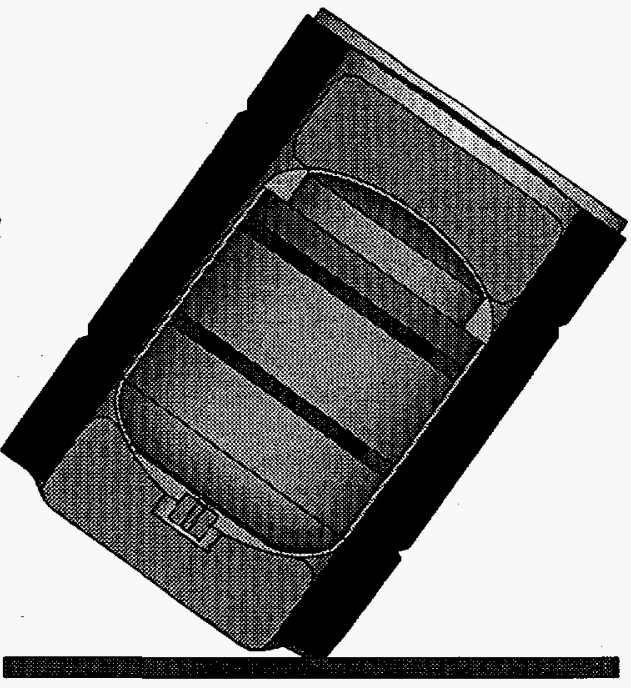

0.090 in. $(2.3 \mathrm{~mm})$

FIGURE 7: DEFORMED SHAPES WITH VARIOUS LID THICKNESS AFTER A 30 FOOT DROP

TABLE 4: AT-400A STRUCTURAL ANALYSES

\begin{tabular}{|c|c|c|c|}
\hline Analysis & Orientation & $\begin{array}{c}\text { Foam } \\
\text { Properties }\end{array}$ & $\begin{array}{c}\text { FE } \\
\text { Model }\end{array}$ \\
\hline \multirow{3}{*}{ drop } & \multirow{2}{*}{ side } & static & 3 \\
\hline & & \multirow[b]{2}{*}{ dynamic } & 3 \\
\hline & $\begin{array}{c}\text { side }-1^{\circ} \text { from hor- } \\
\text { izontal }\end{array}$ & & 3 \\
\hline bottom down drop & \multirow{3}{*}{ CG-over-corner } & \multirow{3}{*}{ dynamic } & \multirow{3}{*}{3} \\
\hline top down drop & & & \\
\hline $\begin{array}{l}\text { top down - lid thick- } \\
\text { ness parametric study }\end{array}$ & & & \\
\hline \multirow{3}{*}{ drop } & \multirow{3}{*}{ top down } & \multirow{3}{*}{ dynamic } & 1 \\
\hline & & & 2 \\
\hline & & & 3 \\
\hline \multirow{2}{*}{ crush } & \multirow{2}{*}{ side } & static & \multirow{2}{*}{3} \\
\hline & & dynamic & \\
\hline crush - top up & \multirow{2}{*}{ CG-over-comer } & \multirow{2}{*}{ dynamic } & \multirow{2}{*}{3} \\
\hline crush - bottom up & & & \\
\hline crush & vertical (top up) & dynamic & 3 \\
\hline
\end{tabular}

TABLE 5: COMPARISON IN CV REDUCTION IN DIAMETER $1^{\circ}$ VS. $0^{\circ}$ SIDE DROP

\begin{tabular}{|c|c|c|c|}
\hline CV Location & Side (in.) & 1 Degree (in.) & \% Difference \\
\hline \hline top & 0.2381 & 0.1980 & -16.8 \\
\hline mid top & 0.2294 & 0.1693 & -26.2 \\
\hline middle & 0.2613 & 0.1714 & -34.4 \\
\hline mid bottom & 0.1996 & 0.1399 & -29.9 \\
\hline bottom & 0.0282 & 0.0128 & -54.5 \\
\hline
\end{tabular}

The trend of having more $\mathrm{CV}$ deformation with stronger foam properties was demonstrated in several analyses. Table 6 shows the reduction in diameter for both static (weaker) and dynamic (stronger) foam properties in a side crush simulation using FE Model 3. The stronger foam properties cause significantly more deformation in the $\mathrm{CV}$.

TABLE 6: COMPARISON IN CV DIAMETER REDUCTION STATIC VS. DYNAMIC FOAM PROPERTIES

\begin{tabular}{|c|c|c|c|}
\hline \multirow{2}{*}{ CV Location } & \multicolumn{2}{|c|}{ Reduction in Diameter (in. (mm)) } & \multirow{2}{*}{$\begin{array}{c}\% \\
\text { Difference }\end{array}$} \\
\hline & Static Props & Dyn. Props & \\
\hline top & $0.389(9.9)$ & $0.535(13.6)$ & 37.5 \\
\hline mid top & $0.332(8.4)$ & $0.405(10.3)$ & 22.0 \\
\hline middle & $0.368(9.3)$ & $0.473(12.0)$ & 28.5 \\
\hline mid bottom & $0.299(7.6)$ & $0.350(8.9)$ & 17.0 \\
\hline bottom & $0.043(1.1)$ & $0.111(2.8)$ & 158.1 \\
\hline
\end{tabular}




\section{Drop Versus Crush Simulations}

All of the drop test simulations show plastic strains less than the crush simulations. For a drop simulation, the highest strains in the $\mathrm{CV}$ are seen in the top (or bottom) drop orientation. It was observed in testing that the top drop is also the most damaging orientation for the aluminum transition flange. Although the goal of these analyses was not to examine the contents support structure in detail, three were done to study CV accelerations in a top drop with the idea that lower CV accelerations produce lower loads on the contents and transition flange.

Figure 10 is a plot of CV flange accelerations for three FE models. The first, FE Model 1, uses a foam density of $30 \mathrm{lb} / \mathrm{ft}^{3}\left(480 \mathrm{~kg} / \mathrm{m}^{3}\right)$ in the top insert cover and incorporates the lid ring with solid elements. FE model 2 and 3 use a foam density of $15 \mathrm{lb} / \mathrm{ft}^{3}\left(240 \mathrm{~kg} / \mathrm{m}^{3}\right)$ and $30 \mathrm{lb} / \mathrm{ft}^{3}$ $\left(480 \mathrm{~kg} / \mathrm{m}^{3}\right)$, respectively, but do not incorporate the solid elements for the lid ring. The shell thickness is changed to represent the ring. FE Model 3 has the highest acceleration, since there was no lid ring and the higher density foam does not absorb as much energy. Figure 8 shows how the lid in FE Model 1 absorbs energy during impact while $\mathrm{FE}$ Model 3 does not capture this deformation. The peak accelerations between FE Models 1 and 2 are within 10\%, but the rise time is slower on Model 1 because the lid is able to deform and absorb energy as the top insert and CV move toward the target.

FE Model 3 without lid ring

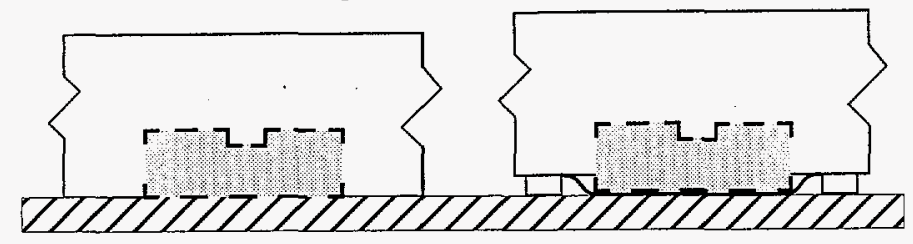

FIGURE 8: DIFFERENCES IN DEFORMATION WITH AND WITHOUT LID RING

\section{Drum Deformations}

It is not straightforward to identify a worst case orientation when considering the drum. The CG-over-corner drop test simulations predict large lid deformations, but the CG-over-corner crush test simulations predict large concentrated deformations at the corners of the drum or leaktightness of the CV. Neither of these orientations threatens to breach the confinement of the drum. However, recall that these simulations do not accurately model the bolts that attach the drum lid. It was observed in testing that several lid bolts sheared. Thus, these simulations probably do not include enough detail to conclude that one condition is worse than another when considering the drum.

\section{CONCLUSION}

The FE model of the AT- $400 \mathrm{~A}$ was validated by comparing simulations to test data. The validation used both qualitative and quantitative measures of comparison. Quantitative comparisons showed good agreement between measured and predicted $\mathrm{CV}$ accelerations, $\mathrm{CV}$ velocity changes, and lid deformations.
Finally, it has been demonstrated that the AT-400A FE model calculating with PRONTO3D gives reasonably accurate results. Within the limitations of the approximations and assumptions cited, it appears that the AT-400A CV has a significant safety margin when subjected to the 30 foot $(9 \mathrm{~m})$ drop test and dynamic crush test. The margin of safety is due to the high ductility of the $304 \mathrm{~L}$ vessel material and the low predicted plastic strains. The safety margin of the $\mathrm{CV}$ based on effective plastic strain is approximately 9 .

\section{REFERENCES}

Taylor, L. M. and Flanagan, D. P., "PRONTO3D - A Three-Dimensional Transient Solid Dynamics Program", SAND86-0594, Sandia National Laboratories, 1987.

PDA Engineering, 1987, PATRAN Plus User's Manual, Volumes I and II, Release 2.4., PDA Engineering, Costa Mesa, CA

Military Handbook, "Metallic Materials and Elements for Aerospace Vehicle Structures", Department of Defense, Volumes I and II, MILHDBK-5E, June 1, 1987. 

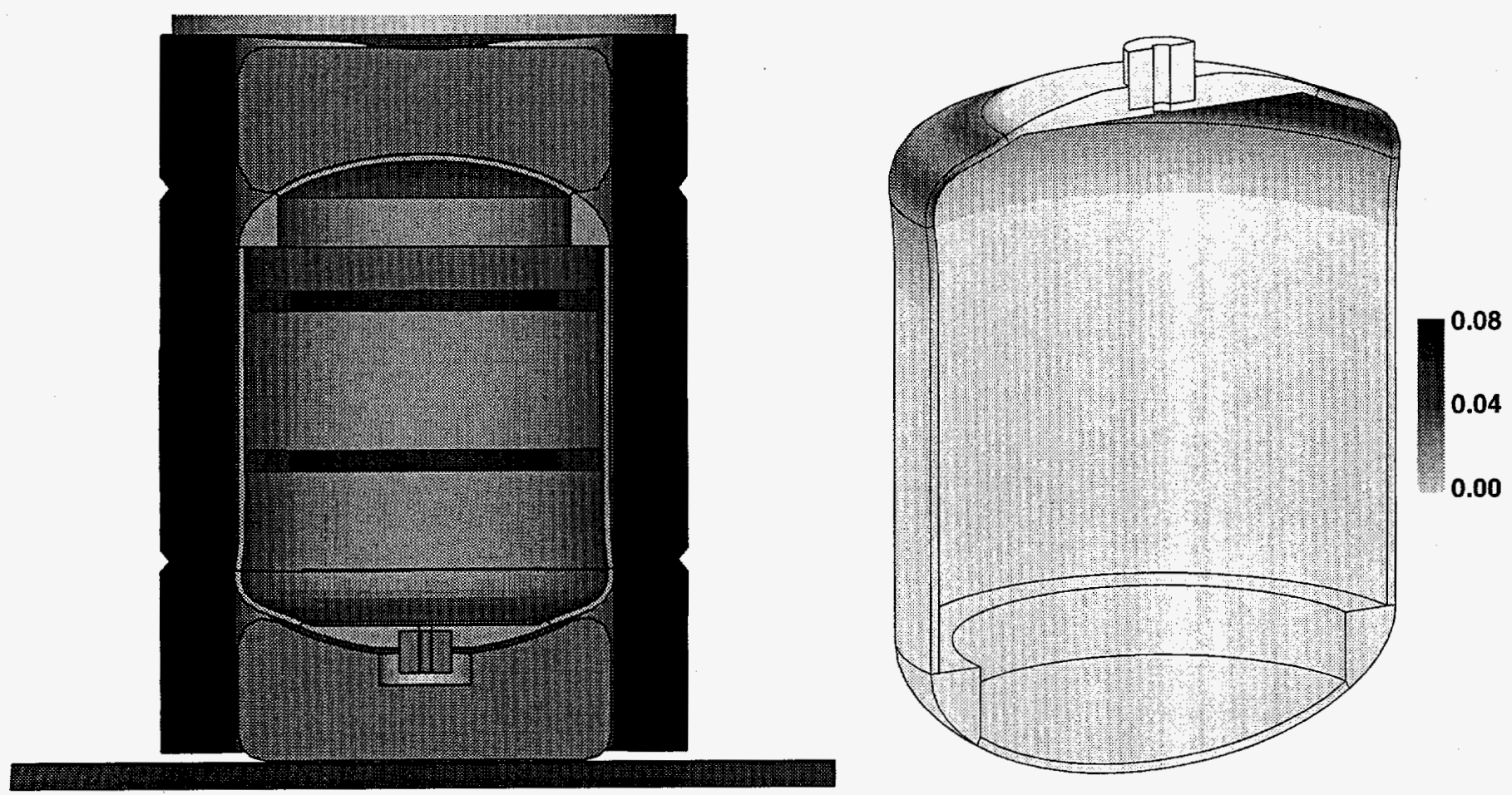

FIGURE 9: DEFORMED SHAPE AND EQUIVALENT PLASTIC STRAIN DURING A 30-FOOT TOP DROP

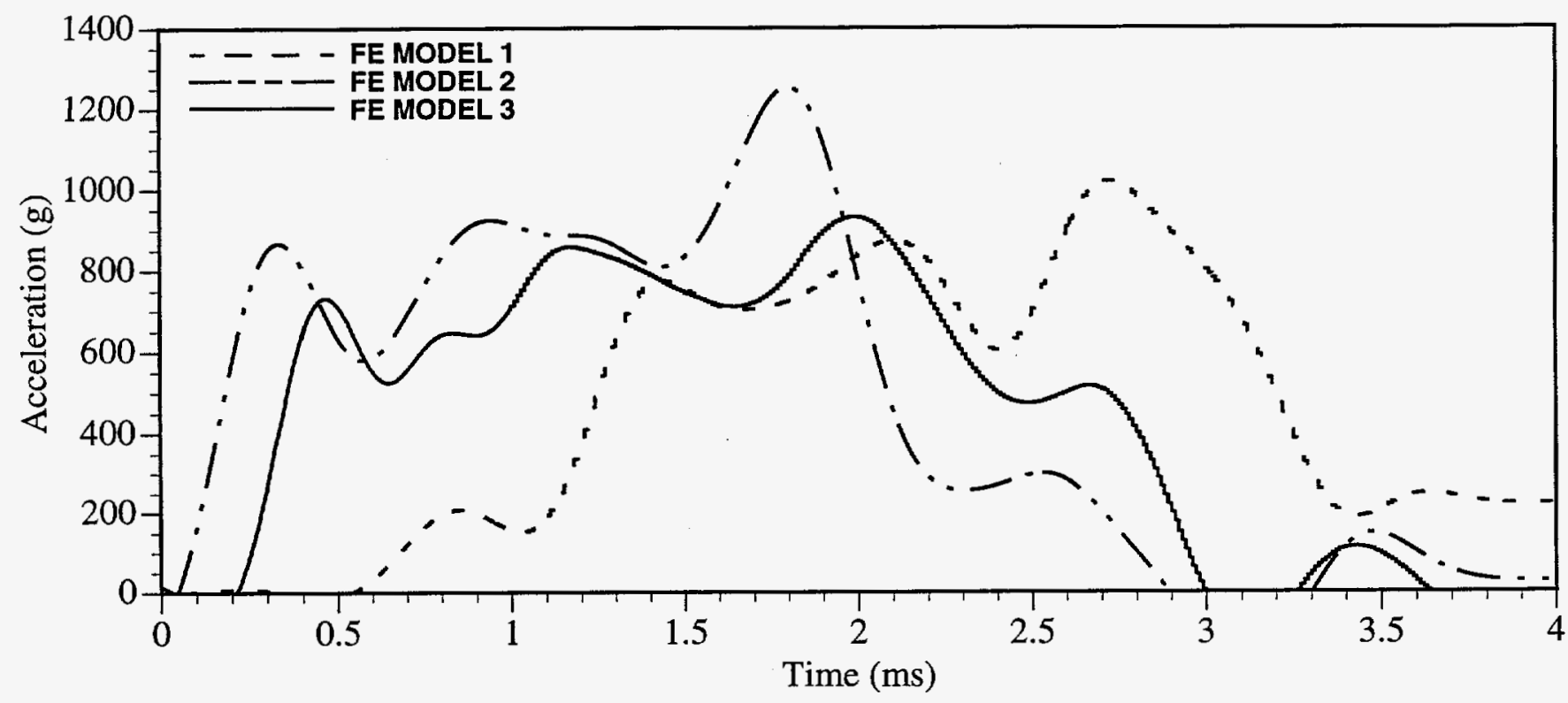

FIGURE 10: CV FLANGE ACCELERATION FOR THREE DIFFERENT TOP DROP SIMULATIONS 

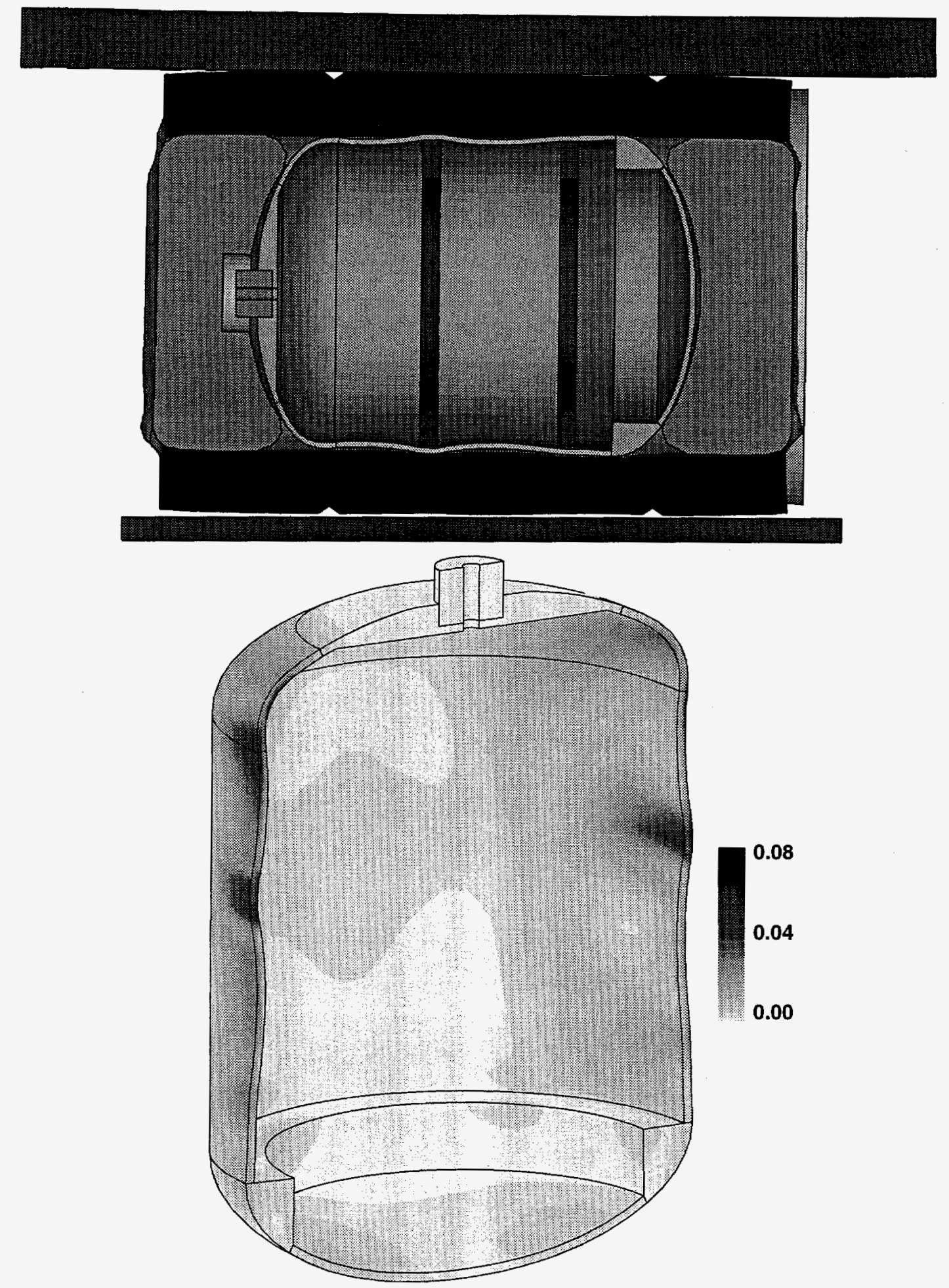

FIGURE 11: DEFORMED SHAPE (TOP) AND EQUIVALENT PLASTIC STRAIN (BOTTOM) AFTER THE SIDE CRUSH SIMULATION 